\author{
BULETINUL INSTITUTULUI POLITEHNIC DIN IAŞI \\ Publicat de \\ Universitatea Tehnică „Gheorghe Asachi” din Iaşi \\ Volumul 67 (71), Numărul 4, 2021 \\ Secţia \\ CONSTRUCȚII DE MAȘINI \\ DOI:10.2478/bipcm-2021-0020
}

Sciendo

\title{
PROFILING OF THE GENERATING RACK OF AN ORDERED CURL KNOWN IN DISCRETE FORM BY THE VIRTUAL POLE METHOD
}

BY

\section{GEORGIANA-ALEXANDRA MOROȘANU*, VIRGIL-GABRIEL TEODOR and NICOLAE OANCEA}

"Dunărea de Jos" University of Galați, Romania

Faculty of Engineering

Received: September 30, 2021

Accepted for publication: December 2, 2021

\begin{abstract}
Situations encountered in "reverse engineering" are relatively common in which, to address a problem of profiling generating tools for processing an orderly curl of surfaces (cylindrical or helical teeth), data known by measuring the existing product are used. The surface numerical representation can be done in the form of a points cloud. The profiling algorithm proposed in the paper is based on the possibility of measuring surfaces and their representation through an ordered cloud of points. The algorithm uses the complementary theorem of the virtual pole, for profiling the rack tool generating a piece that has an ordered curl of profiles. The methodology is not limited to the profiling of the rack tool but can be extended to the problem of profiling the primary peripheral surface of some screw-type tools, generating the ordered curl of surfaces. The paper also presents a numerical application developed based on a specific software product.
\end{abstract}

Keywords: enwrapping generating method; discreet profile; ordered cloud; complementary theorem; rack tool.

*Corresponding author; e-mail: Alexandra.Costin@ugal.ro (C) 2021 Georgiana-Alexandra Moroșanu et al.

This is an open access article licensed under the Creative Commons Attribution-NonCommercialNoDerivatives 4.0 International License (CC BY-NC-ND 4.0). 


\section{Introduction}

The numerical representation of a surface can be done in the form of a point cloud. The coordinates of these points can be determined using coordinate measuring machines or three-dimensional scanning equipments.

In the case of cylindrical teeth, the identification succession of these points can be chosen in such a way that they are ordered along a guiding curve of the flank, thus ensuring the obtaining of points strings which have the property of being in the same plane. The respective plane can be chosen so as to be perpendicular to the axis of the teeth (Radzevich, 2007). In this way a surface directory can be obtained, a curve known in discrete form (Oancea et al., 2006a, Oancea et al., 2006b) and which, for a sufficiently large number of points, can be accepted that it models accurately enough the measured physical surface.

Another acceptable solution is that in which the points measured on successive surfaces lead to ordered clouds of points, which allow a polyhedral modeling of the inspected surface (Fig. 1).

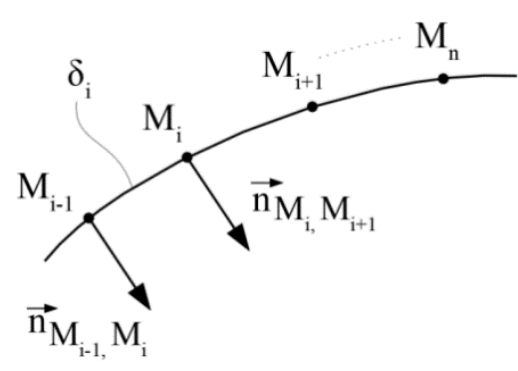

$a$

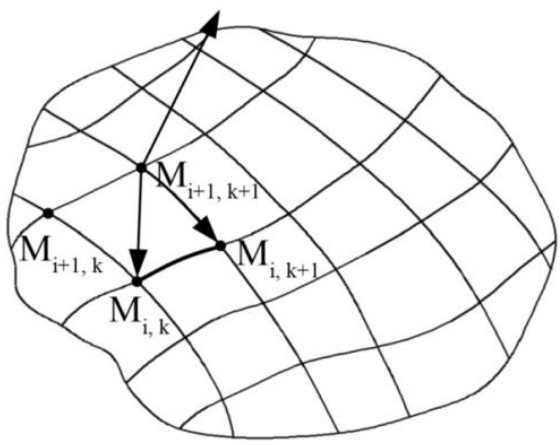

$b$

Fig. 1 - Discrete form representations of curves and surfaces: discrete substitutive segments $\left(\delta_{i}\right)(a)$; polyhedral shaped surface $(b)$.

In both cases, modeling is an approximation, but has the advantage of allowing the definition of a local normal at a point belonging to the surface.

This allows the use of one of the fundamental theorems (Gohman, Olivier or Willis (Litvin, 1989)) or a complementary theorem: substitute circles, minimum distance method or in-plane generating trajectories (Oancea, 2004).

All analytical methods are based on the kinematic expression of the enwrapping condition according to which, in the relative movement of two mutually enveloping curves associated with a couple of rolling centrodes, a point belongs to the envelope of the family of curves generated in relative movement if at that point the normal to the curve is perpendicular to the relative speed vector. 
In the case of modeling curves, if elementary segments $\delta_{i}=M_{i-1} M_{i}$ see Fig. 1 , are small enough $\left(\delta_{i}=10^{-2} \div 10^{-3} \mathrm{~mm}\right)$, the technically acceptable approximation can be considered.

Similarly, in the case of polyhedral surface modeling, vectors $\overline{M_{i+1, k+1} M_{i, k}}$ and $\overline{M_{i+1, k+1} M_{i, k+1}}$, respectively, can be used to define the local normal, at the point $M_{i+l, k+1}$, at the surface:

$$
\vec{n}_{i+1, k+1}=\overrightarrow{M_{i+1, k+1} M_{i, k}} \cdot \overrightarrow{M_{i+1, k+1} M_{i, k+1}} .
$$

And in this case, for the approximation to be acceptable, it is necessary that the modules of the vectors $\overrightarrow{M_{i+1, k+1} M_{i, k}}$ and $\overrightarrow{M_{i+1, k+1} M_{i, k+1}}$ to be quite small $\left(10^{-2} \div 10^{-3} \mathrm{~mm}\right)$.

The paper approaches the issue of profiling the rack tool generating an ordered vortex of cylindrical surfaces with discrete represented director through points whose coordinates can be determined by 3D scanning.

The algorithm used is the virtual pole method (Costin et al., 2019). The virtual pole (Teodor et al., 2019) represents an intersection point of the normal at a profile of the blank to be generated with the centrode associated with the piece.

The virtual pole is defined as the intersection point between the normal profile and the conjugated centrode. The method allows the establishment of the points belonging to the envelope of the profile to be generated by determining the moment in which the virtual pole overlaps on the gearing pole. Specifically, it determine the parameter with which the profile to be generated must be moved so that the virtual pole coincides with the gearing pole and, using the rolling condition, calculate the second independent parameter, which determines the movement of the tool's profile (generated profile) so that the two profiles mentioned to admit the common normal. By applying the coordinate transformation from the piece reference system to the tool reference system, the coordinates of the current point in the tool reference system are determined.

Other known methods for profiling the tools that generate by rolling, such as the Gohman theorem, the Willis theorem or the minimum distance method, require writing relative movements between the tool and the piece, movements that usually have a complicated form, which can lead to errors.

The virtual pole method requires only the writing of the absolute movements of the piece and the tool, eliminating the need to determine the relative movement between these two elements. This eliminates an important source of errors. The virtual pole method has been extensively described in the paper (Costin et al., 2019). 


\section{Substitutive Point Cloud of the Surface to be Generated}

Fig. 2 shows the centrodes associated with the two reciprocally enveloping surfaces and the reference systems: $X Y$ - mobile reference system joined with the piece`s profile; $x y$ - fixed reference system; $\xi \eta$ - mobile reference system joined with the tool's profile.

The $S$ curve is the primary peripheral surface of the generating tool and is unknown at the initial time. The $\Sigma$ curve is the profile to be generated and is modeled (substituted) by a cloud of points whose coordinates were determined by scanning.

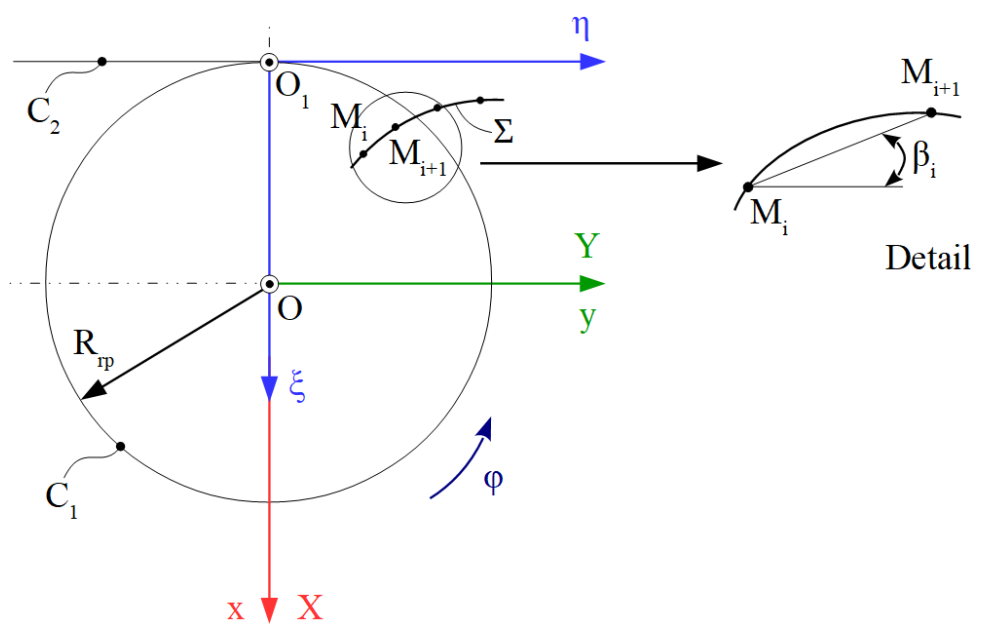

Fig. 2 - The $C_{1}$ and $C_{2}$ centrodes and the approximation of curve $\Sigma$.

Generating with rack tool is a plane enwrapping problem, therefore, the enveloping can be studied in a plane perpendicular to the rotation axis of the blank. In this way, the problem is simplified and the modeling of the surface to be generated can be reduced to the modeling of a plane curve that represents the director of this surface.

The $\Sigma$ curve can be discreetly modeled by the point cloud:

$$
\Sigma:\left(\begin{array}{cc}
X_{1} & Y_{1} \\
X_{2} & Y_{2} \\
\vdots & \vdots \\
X_{n} & Y_{n}
\end{array}\right)
$$

The coordinates $\left[X_{i}, Y_{i}\right]$ define the position of a point $M_{i}$ belonging to the plane $X O Y$ in which the study of the plane enwrapping is made. 
The length of the segment between the two successive points, $M_{i}$ and $M_{i+1}$ is given by the relation:

$$
\sqrt{\left(X_{i+1}-X_{i}\right)^{2}+\left(Y_{i+1}-Y_{i}\right)^{2}}
$$

The vector corresponding to the $M_{i} M_{i+1}$ points has the form:

$$
\overrightarrow{M_{i} M_{i+1}}=\left(X_{i+1}-X_{i}\right) \cdot \vec{i}+\left(Y_{i+1}-Y_{i}\right) \cdot \vec{j},
$$

where the unitary vectors $\vec{i}$ and $\vec{j}$ corresponds to $X$ and $Y$ axis.

The $M_{i} M_{i+1}$ segment can be expressed in parametric form by:

$$
\Sigma_{i, i+1}: \mid \begin{aligned}
& X(u)=X_{i}+u \cdot \sin \beta_{i} ; \\
& Y(u)=Y_{i}+u \cdot \cos \beta_{i},
\end{aligned} \quad i=1, \ldots, n,
$$

with $u$ variable scalar parameter between the limits $u_{\min }=0 ; u_{\max }=\delta_{i}$ and $\operatorname{tg} \beta_{i}=\frac{Y_{i}-Y_{i+1}}{X_{i}-X_{i+1}}$.

Eq. (5) determine the substitutive elementary profile $\Sigma_{i, i+1}$ of the generating curve.

\subsection{The Normal to the Substitute Elementary Segment and the Condition for Determining the Virtual Pole}

From Eq. (5), the directors parameters of the normal to the elementary profile $\Sigma_{i, i+1}$ are defined:

$$
\overrightarrow{n_{\Sigma}}=\left|\begin{array}{cc}
\vec{i} & \vec{j} \\
\dot{X}_{u} & \dot{Y}_{u}
\end{array}\right|=\dot{Y}_{u} \cdot \vec{i}-\dot{X}_{u} \cdot \vec{j}
$$

In this way, the normal to the elementary substitution segment can be:

$$
\vec{N}_{\Sigma_{i, i+1}}=\left(X_{i}+\lambda \cdot \dot{Y}_{u}\right) \cdot \vec{i}+\left(Y_{i}-\lambda \cdot \dot{X}_{u}\right) \cdot \vec{j},
$$

where $\lambda$ is the scalar parameter whose size depends on the modulus of the vector $\vec{N}$. 
Thus, the intersection condition of the normal at the substitutive elementary segment with the centrode associated with the vortex of surfaces can be defined. The parametric equations of the $C_{l}$ centrode, see also Fig. 2, are:

$$
C_{l}: \mid \begin{aligned}
& X=-R_{r p} \cdot \cos \varphi \\
& Y=R_{r p} \cdot \sin \varphi,
\end{aligned}
$$

where $R_{r p}$ is the rolling radius of the piece and $\varphi$ is the angular parameter which defines the rotation of the reference system joined with the piece around Z-axis, see Fig. 2.

The minimum value of the rolling radius of the piece is determined from the condition that the normal at any point of the substitutive generator intersects of the $C_{l}$ centrode. It can be accepted as the size of the radius $R_{r p}$, the radius of the outer circle of the vortex ordered by the $\Sigma$ profiles.

From Eq. (7) and (8) results the condition for determining the virtual pole in the form:

$$
\left\{\begin{array}{l}
-R_{r p} \cdot \cos \varphi=X_{i}+\lambda \cdot \dot{Y}_{u} \\
R_{r p} \cdot \sin \varphi=Y_{i}-\lambda \cdot \dot{X}_{u},
\end{array}\right.
$$

or, after successive processing:

$$
\begin{aligned}
& \lambda=\frac{-R_{r p} \cdot \cos \varphi-X_{i}}{\dot{Y}_{u}}=\frac{-R_{r p} \cdot \sin \varphi+Y_{i}}{\dot{X}_{u}} \Rightarrow \\
& \Rightarrow\left(-R_{r p} \cdot \cos \varphi-X_{i}\right) \cdot \dot{X}_{u}=\left(-R_{r p} \cdot \sin \varphi+Y_{i}\right) \cdot \dot{Y}_{u} \Rightarrow \\
& \Rightarrow\left(-R_{r p} \cdot \sin \varphi+Y_{i}\right) \cdot \dot{Y}_{u}+\left(R_{r p} \cdot \cos \varphi+X_{i}\right) \cdot \dot{X}_{u}=0 \Leftrightarrow \\
& \Leftrightarrow\left(R_{r p} \cdot \cos \varphi+X_{i}\right) \cdot \dot{X}_{u}-\left(R_{r p} \cdot \sin \varphi-Y_{i}\right) \cdot \dot{Y}_{u}=0,
\end{aligned}
$$

for $\left(X_{i}, Y_{i}\right) i=1, \ldots, n$.

The set of the absolute movement equations is:

$$
x=\omega_{3}^{T}(\varphi) \cdot X,
$$


where $X$ has the elements given by (5) and the condition (10) determines the gearing curve.

\subsection{The Flank of the Generating Rack}

Basically, the gearing curve is defined in the fixed reference system, in the form:

$$
\text { C.A.: } \mid \begin{aligned}
& x=x(u, \varphi) ; \\
& y=y(u, \varphi) ; \\
& \varphi=\varphi(u) .
\end{aligned}
$$

The gearing curve is the geometric locus in the fixed reference system of the contact points between the substitutive point cloud of the profile to be generated and the generating tool profile.

Transferring the points on the gearing curve to the system associated with the tool, $\xi \eta$, the flank of the generating rack is determined.

For this, the points on the gearing curve are given the absolute movement:

$$
\xi=x+A ; \quad A=\left(\begin{array}{c}
-R_{r p} \\
-R_{r p} \cdot \varphi
\end{array}\right) .
$$

\section{Numerical Application}

A numerical application has been developed for profiling the rack tool intended for machining a profile known in discrete form.

The profile is a freeform curve obtained by measurement on a Starrett Optical horizontal profile projector.

Fig. 3 shows the profile`s piece and the reference systems used. The rolling radius is $R_{r p}=50 \mathrm{~mm}$. 


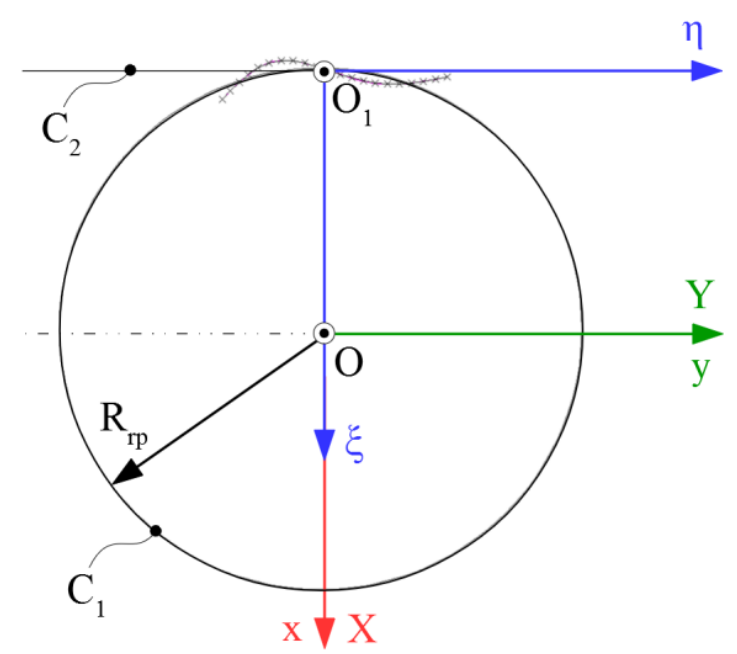

Fig. 3 - The piece profile and the reference systems.

Fig. 4 shows the profile of the generating tool made in Octave program. The coordinates of the measured points have been saved in a *xls file, and the calculation program reads the respective points from that file.

In Fig. 4, the green curve represents the piece profile, the blue one represents the contact curve and the red one is the profile of the rack tool.

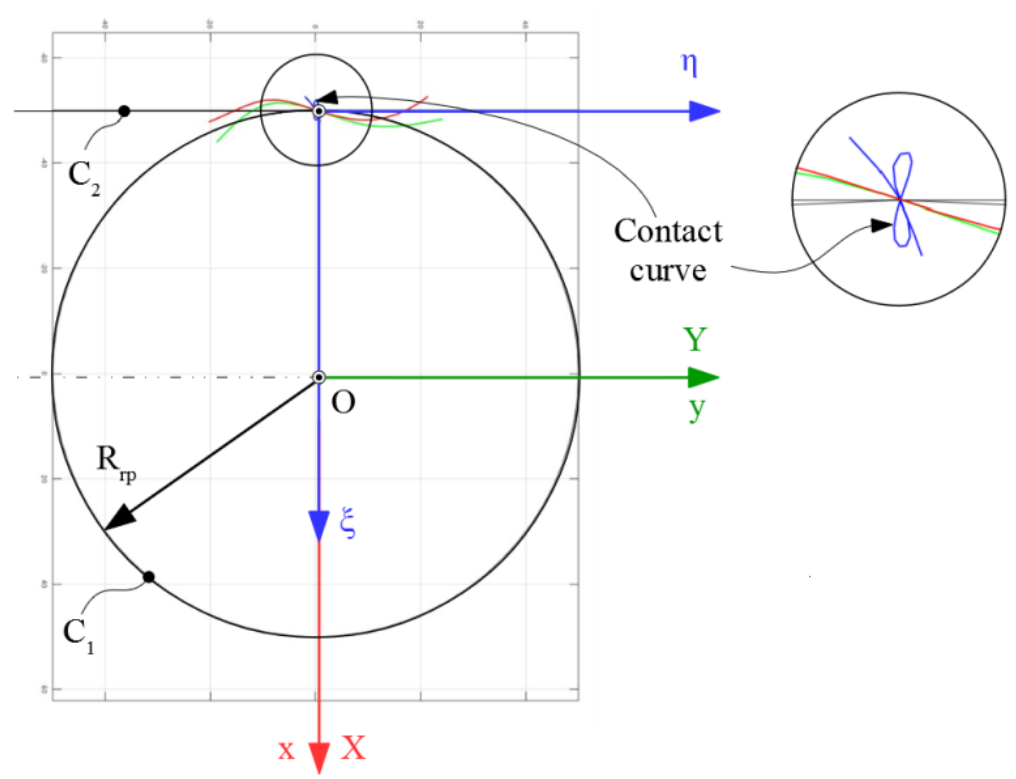

Fig. 4 - The profile of the generating tool and the contact curve. 
In Table 1 are presented the coordinates of the rack tool profile and the piece profile.

Table 1

The Coordinates of the Rack Tool Profile and the Piece Profile

\begin{tabular}{|c|c|c|c|c|}
\hline \multirow{2}{*}{ No. } & \multicolumn{2}{|c|}{ Tool profile } & \multicolumn{2}{|c|}{ Piece profile } \\
\hline & $\xi$ & $\eta$ & $\mathrm{X}$ & $\mathrm{Y}$ \\
\hline 1 & 22.569 & -20.309 & -43.882 & -18.830 \\
\hline 2 & 13.113 & -18.085 & -45.547 & -17.217 \\
\hline 3 & 0.33543 & -15.932 & -47.165 & -15.558 \\
\hline 4 & -0.597 & -13.818 & -48.678 & -13.803 \\
\hline 5 & -13.898 & -11.689 & -49.994 & -11.898 \\
\hline 6 & -18.944 & -94.953 & -50.961 & -9.796 \\
\hline 7 & -19.388 & -7.256 & -51.392 & -7.525 \\
\hline 8 & -15.727 & -50.471 & -51.311 & -5.212 \\
\hline 9 & -0.969 & -28.745 & -50.885 & -2.935 \\
\hline 10 & -0.261 & -0.701 & -50.257 & -0.705 \\
\hline 11 & 0.452 & 15.099 & -49.526 & 1.495 \\
\hline 12 & 10.922 & 37.772 & -48.769 & 3.686 \\
\hline 13 & 15.882 & 61.051 & -48.053 & 5.890 \\
\hline 14 & 18.639 & 84.819 & -47.445 & 8.126 \\
\hline 15 & 1.834 & 10.877 & -47.029 & 10.405 \\
\hline 16 & 14.558 & 13.238 & -46.851 & 12.715 \\
\hline 17 & 0.765 & 15.508 & -46.886 & 15.032 \\
\hline 18 & -0.184 & 17.64 & -47.093 & 17.340 \\
\hline 19 & -13.238 & 19.601 & -47.429 & 19.633 \\
\hline 20 & -25.875 & 21.371 & -47.849 & 21.912 \\
\hline 21 & - & - & -48.310 & 24.184 \\
\hline
\end{tabular}

\section{Conclusions}

In conclusion, in the paper was presented a variant for determining the enwrapping condition in the case of the rack tool designed to process a profile known in discrete form.

The virtual pole method is easier to apply, while remaining scientifically rigorous. By applying the proposed algorithm, it is no longer necessary to write explicitly the relative movements between the tool and the piece, which simplifies the calculation process and eliminates some of the possibilities for errors. It should be noted that the new algorithm doesn't eliminate the relative movements influence. It only eliminate the need to write the relative movements in an explicit form and therefore the need to work with relatively complicated equations. 
Acknowledgements. This work is supported by the project ANTREPRENORDOC, in the framework of Human Resources Development Operational Programme 2014-2020, financed from the European Social Fund under the contract number 36355/23.05.2019 HRD OP /380/6/13 - SMIS Code: 123847.

\section{REFERENCES}

Costin G.A., Teodor V.G., Oancea N., Virtual Pole Method - Alternative Method for Profiling Tools which Generate by Enwrapping, The Ann. of "Dunărea de Jos" University of Galati, Fasc. V, 5, 31-34, Technologies in Machine Building (2019).

Litvin F.L., Theory of Gearing, NASA Reference Publications 1212 (AVSCOM Technical Report 88 C 135), 1989.

Oancea N., Generarea suprafețelor prin infăş̧urare. Teoreme complementare (Surface generation trough winding. Complementary theorems), vol. II, „Dunărea de Jos" University Publishing House, 2004.

Oancea N., Teodor V., Cucu M., Discretly Known Reciprocally Enwrapping Surfaces Representation Model - Surface's Polyhedron Representation Method, Bul. Inst. Polit. Iaşi, LII(LVI), 222-228, Constr. de Maș. (2006).

Oancea N., Teodor V., Cucu M., Discretly Known Reciprocally Enwrapping Surfaces Representation Model - Algorithms, Bul. Inst. Polit. Iaşi, LII(LVI), 217-221, Constr. de Maș. (2006).

Radzevich S., Kinematic Geometry of Surface Machining, CRC Press, Boca Raton, London, ISBN 978-1-4200-6340-0, 2007.

Teodor V.G., Costin G.A., Virtual Pole Method - Alternative Method for Profiling Rack Tools, The Ann. of "Dunărea de Jos" University of Galați, Fasc. V, 5, 5-8, Technologies in Machine Building (2019).

\section{PROFILAREA CREMALIEREI GENERATOARE A UNUI VÂRTEJ ORDONAT, CUNOSCUT ÎN FORMĂ DISCRETĂ, PRIN METODA POLULUI VIRTUAL}

\section{(Rezumat)}

Sunt relativ frecvente situaţiile întâlnite în „,ingineria inversă” în care, pentru abordarea unei probleme de profilare a sculelor generatoare pentru prelucrarea unui vârtej ordonat de suprafeţe (danturi cilindrice sau elicoidale) se utilizează date cunoscute prin măsurarea produsului existent. Reprezentarea numerică a unei suprafețe se poate face sub forma unui nor de puncte. Algoritmul de profilare propus în lucrare se bazează pe posibilitatea măsurării suprafețelor şi reprezentarea acestora printr-un nor ordonat de puncte. Algoritmul utilizează teorema complementară a polului virtual, pentru profilarea sculei cremalieră generatoare a unui reper care prezintă un vârtej ordonat de profiluri. Metodica nu este limitată la profilarea sculei cremalieră ci poate fi extinsă şi la problematica profilării suprafeței periferice primare a unor scule de tip melc, generatoare a vârtejului ordonat de suprafețe. În lucrare se prezintă şi o aplicaţie numerică dezvoltată în baza unui produs soft specific. 